\title{
Update on Asthma-COPD Overlap (ACO): A Narrative Review
}

\author{
Evgeni Mekov' \\ Alexa Nuñez $\mathbb{D}^{2}$ \\ Don D Sin (iD) \\ Masakazu Ichinose ${ }^{4}$ \\ Chin Kook Rhee $\mathbb{D}^{5}$ \\ Diego Jose Maselli ${ }^{6}$ \\ Andréanne Coté ${ }^{7}$ \\ Charlotte Suppli Ulrik $\mathbb{D}^{8,9}$ \\ François Maltais $\mathbb{D}^{7}$ \\ Antonio Anzueto ${ }^{6}$ \\ Marc Miravitlles (D) ${ }^{2}$ \\ 'Department of Occupational Diseases, \\ Medical Faculty, Medical University of \\ Sofia, Sofia, Bulgaria; ${ }^{2}$ Pneumology \\ Department, Hospital Universitari Vall d \\ 'Hebron, Vall d'Hebron Institut de Recerca \\ (VHIR), Vall d'Hebron Barcelona Hospital \\ Campus, CIBER de Enfermedades \\ Respiratorias (CIBERES), Barcelona, Spain; \\ ${ }^{3}$ Centre for Heart Lung Innovation, St. Paul's \\ Hospital, Department of Medicine \\ (Respiratory Division), University of British \\ Columbia, Vancouver, BC, Canada; \\ ${ }^{4}$ Academic Center of Osaki Citizen Hospital, \\ Miyagi, Japan; ${ }^{5}$ Division of Pulmonary, Allergy \\ and Critical Care Medicine, Department of \\ Internal Medicine, Seoul St. Mary's Hospital, \\ College of Medicine, The Catholic University \\ of Korea, Seoul, Republic of Korea; ${ }^{6}$ Division \\ of Pulmonary Diseases \& Critical Care, \\ University of Texas Health, South Texas \\ Veterans Health Care System, San Antonio, \\ TX, USA; ${ }^{7}$ Institut Universitaire de \\ Cardiologie et de Pneumologie de Québec, \\ Université Laval, Québec, QC, Canada; \\ ${ }^{8}$ Department of Pulmonary Medicine, \\ Copenhagen University Hospital-Hvidovre, \\ Hvidovre, Denmark; ${ }^{9}$ Institute of Clinical \\ Medicine, University of Copenhagen, \\ Copenhagen, Denmark
}

Correspondence: Marc Miravitlles Pneumology Department, Hospital Universitari Vall d'Hebron, Vall d'Hebron Institut de Recerca (VHIR), Vall d'Hebron Barcelona Hospital Campus, CIBER de

Enfermedades Respiratorias (CIBERES),

Barcelona, Spain

Email marcm@separ.es
Abstract: Although chronic obstructive pulmonary disease (COPD) and asthma are wellcharacterized diseases, they can coexist in a given patient. The term asthma-COPD overlap (ACO) was introduced to describe patients that have clinical features of both diseases and may represent around $25 \%$ of COPD patients and around $20 \%$ of asthma patients. Despite the increasing interest in ACO, there are still substantial controversies regarding its definition and its position within clinical guidelines for patients with obstructive lung disease. In general, most definitions indicate that ACO patients must present with non-reversible airflow limitation, significant exposure to smoking or other noxious particles or gases, together with features of asthma. In patients with a primary diagnosis of COPD, the identification of ACO has therapeutic implication because the asthmatic component should be treated with inhaled corticosteroids and some studies suggest that the most severe patients may respond to biological agents indicated for severe asthma. This manuscript aims to summarize the current state-of-the-art of ACO. The definitions, prevalence, and clinical manifestations will be reviewed and some innovative aspects, such as genetics, epigenetics, and biomarkers will be addressed. Lastly, the management and prognosis will be outlined as well as the position of ACO in the COPD and asthma guidelines.

Keywords: ACO, asthma, COPD, epidemiology, genetics, biomarkers, prognosis, treatment

\section{Introduction}

Although chronic obstructive pulmonary disease (COPD) and asthma are distinct entities, they can coexist in a given patient. The term asthma-COPD overlap (ACO) was introduced to describe these patients. In some patients, the overlap appears obvious, such as COPD patients who demonstrate a particular phenotype that is characterized by a predominant type 2 (T2) inflammation, and manifest clinical characteristics associated with asthma, such as significant reversibility and increased number of eosinophils in peripheral blood and the airways, while in others, the clinical expression of the overlap is more subtle. ${ }^{1}$ ACO may represent between $10 \%$ and $40 \%$ of COPD patients and between $15 \%$ and $35 \%$ of asthma patients. ${ }^{2}$

The concept of overlap between COPD and asthma is not new and dates back to 1961 with Orie's "Dutch hypothesis", 3 which acknowledged the coexistence of biological, physiological and clinical characteristics of asthma and COPD in some patients. In 2007, the Canadian COPD guidelines adopted tailored management in patients who expressed features of both asthma and COPD, ${ }^{4}$ and two years later Gibson and Simpson named this condition an overlap syndrome. ${ }^{5}$ In 2014 , the Global Initiative for Asthma (GINA) and the Global Initiative for Chronic Obstructive Lung Disease (GOLD) published a joint document on a "asthma 
COPD overlap syndrome (ACOS)", which was defined as the presence of persistent airflow limitation with several features usually associated with asthma and several features usually associated with COPD. ${ }^{6}$ The next step was to remove the word "syndrome" from ACOS to become "ACO" since it was considered to have several different clinical manifestations, which did not fulfil all the criteria of a syndrome. ${ }^{7}$

Since the publication of the GINA-GOLD document in 2014, there has been a growing interest in research in ACO, with the number of articles included in PubMed increasing from 91 in 2014 to 502 by the end of 2020 . Despite this increase in the interest in ACO, there are still some controversial issues around this concept. Among them, there is no universally accepted definition, and GOLD 2020 for the first time no longer refers to ACO; instead, it emphasizes that asthma and COPD are different disorders, although they may share some common traits and clinical features (eg, elevated blood eosinophil count, partial reversibility), and they could also coexist in an individual patient. ${ }^{8}$ In this context, it is relevant to summarize the current knowledge about the different aspects of ACO, which may help to better define it and establish the best therapeutic strategies for patients suffering from this condition.

This manuscript summarizes the current state-of-the-art of ACO. The definitions, prevalence, and clinical manifestations will be reviewed and innovative aspects such as genetics, epigenetics, and biomarkers will be addressed. Lastly, the prognosis and management will be outlined as well as the position of ACO in the COPD guidelines.

\section{Definition of ACO}

During the last decade, there have been several definitions of ACO. Most of these definitions recognize that there are individuals with smoking-related COPD on a background of T2 inflammation expressed as increased eosinophil counts in sputum and/or peripheral blood, and/or significant reversibility of airflow to short-acting 32 -agonists. ${ }^{1,9,10}$ These patients could be defined as a particular phenotype of COPD called ACO because of their resemblance to asthma, COPD with features of T2 inflammation or eosinophilic COPD. ${ }^{11}$ Other subjects suffering from asthma with significant exposure to smoking may lead to the development of some unique characteristics of COPD, ie not fully reversible airflow obstruction, reduction in diffusing capacity of the lungs for carbon monoxide (DLCO), and emphysema on computed tomography scans. These individuals could also be considered to have ACO. ${ }^{11-13}$ It is important to highlight that significant smoking (or other noxious) exposure is necessary for the diagnosis of COPD, and therefore, of ACO. Otherwise, non-fully reversible airflow limitation in an asthmatic patient in the absence of significant smoking exposure should be diagnosed with chronic, irreversible asthma but not ACO. ${ }^{12,14}$

The heterogeneity of individuals included in the definition of ACO led to the development of many consensus definitions many including key features, namely, non-fully reversible airflow obstruction, significant exposure to smoking or other noxious irritants, plus an asthmatic component defined as previous or current diagnosis of asthma, elevated blood and/or sputum eosinophils or some degree of airflow reversibility. ${ }^{6,15,16}$

The agreement on a consensus definition is crucial to enable comparison of data obtained across different studies around the world. In this respect, the most widely recognized definition of ACO is that of the joint GINA/ GOLD document published in 2014. ${ }^{6}$ The first step in the approach to these patients is the identification of a chronic airway disease based on history, ie, chronic or recurrent cough, sputum production, wheezing, or repeated acute lower respiratory tract infections. In the second step, the features of asthma and those of COPD that best describe the patient (ie, age at onset, pattern of symptoms, results of pulmonary function tests, and findings on chest imaging) must be identified, which in turn, results in a diagnosis of COPD, asthma or $\mathrm{ACO}$, according to the presence of signs and symptoms predominantly of either COPD, asthma or both. In the third step, spirometry is recommended for assessing the obstructive pattern at the initial or a subsequent clinic visit.

In 2016, a global expert panel discussion, comprised of various specialists from North America, Western Europe and Asia, reported a consensus on ACO based on major and minor clinical, spirometric and laboratory criteria (Table 1). ${ }^{15}$ In this report, the authors advocated that patients who meet all three major criteria and at least one minor criterion be considered for the diagnosis of ACO. Because airway reversibility and peripheral blood eosinophil counts were included, this definition would be more quantitative and objective, and easier to implement in daily clinical practice.

Other objective and quantifiable traits of COPD and asthma may be of help in identifying subjects with ACO. 
Table I Criteria for Diagnosis of Asthma-Chronic Obstructive Pulmonary Disease Overlap Syndrome

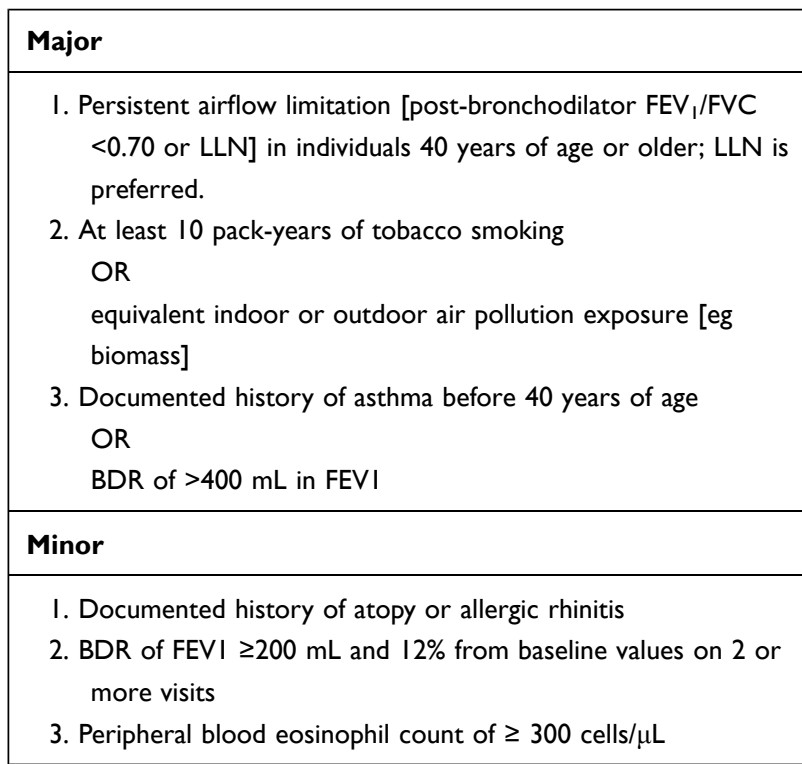

Notes: The committee recommends the presence of all three major criteria and at least one minor criterion for asthma-chronic obstructive pulmonary disease overlap syndrome. FEVI, forced expiratory volume in I s; FVC, forced vital capacity; BDR, bronchodilator response using $400 \mathrm{mg}$ of albuterol/salbutamol [or equivalent]; LLN, Lower limit of normal. Reproduced with permission of the $\odot$ ERS 2021: European Respiratory Journal 48 (3) 664-673; DOI: I0.1 I83/I3993003.00436-2016 Published 3I August 2016. Reproduced from: Sin DD, Miravitlles M, Mannino DM, et al. What is asthma-COPD overlap syndrome (ACOS)? Towards a consensus definition from a roundtable discussion. Eur Respir J. 2016;48: 664-673. ${ }^{15}$ Copyright @ ERS 2016.

Computed tomography (CT, a multi-detector chest CT scanning with deep breath holding in the supine position) of the chest and the pulmonary diffusion capacity of carbon monoxide (DLCO) provide information about gas exchange units (ie alveoli), which may be useful for identifying features of COPD. Fractional exhaled nitric oxide (FeNO), a reliable marker of airway inflammation in asthma, is considered to be a promising diagnostic tool for ACO. ${ }^{17,18}$ In countries such as Japan, where CT is widely used and FeNO measuring devices are clinically applied in more than 2000 facilities, the preferred ACO diagnostic criteria are those that emphasize objective indicators including $\mathrm{CT}$ imaging, DLCO and FeNO as shown in Table 2. ${ }^{19,20}$ Due to the differences in medical resources, country-specific adaptations of the global definition may be required.

In summary, the first step in diagnosing ACO is to confirm a diagnosis of COPD based on smoking (or equivalent noxious exposure) history, respiratory symptoms and presence of non-fully reversible airflow obstruction. Subsequently, the diagnosis of asthma should be confirmed by a well-documented history of asthma and/ or a current diagnosis of asthma according to guidelines. ${ }^{21}$
Table 2 Definition of ACO from Japanese Respiratory Society

\begin{tabular}{|l|}
\hline Basic Characteristics \\
\hline $\begin{array}{l}\text { Post-bronchodilator FEVI/FVC }<70 \% \text { in individuals } 40 \text { years of age or } \\
\text { older }\end{array}$ \\
\hline Features of COPD \\
\hline ( I item out of I-3) \\
\hline I. Smoking history ( $>10$ pack-year) or similar air pollution exposure \\
\hline $\begin{array}{l}\text { 2. Presence of low attenuation area showing emphysematous lesions } \\
\text { on CT }\end{array}$ \\
\hline 3. Impaired pulmonary diffusion (DLCO and/or DLCO/VA <0.8) \\
\hline Features of asthma \\
\hline (2 items out of I-3 or I item out of I-3 and 2 items out of 4 ) \\
\hline I. Variable (diurnal, day to day, seasonal) or paroxysmal respiratory \\
symptoms (cough, sputum, dyspnea) \\
\hline 2. Asthma diagnosis history under 40 years \\
\hline 3. Exhaled nitric oxide $>35$ ppb \\
\hline
\end{tabular}

4-I) Complication of allergic rhinitis

2) Bronchodilator response of $F E V I \geq 200 \mathrm{~mL}$ and $I 2 \%$ from baseline

3) Peripheral blood eosinophil count $>5 \%$ or 300 cells $/ \mu \mathrm{L}$

4) High lgE (for total or inhaled antigens)

Notes: If basic characteristics, features of asthma and features of COPD are satisfied, diagnose as ACO. Reproduced from Yanagisawa S, Ichinose M. Definition and diagnosis of asthma-COPD overlap (ACO). Allergol Int. 2018;67(2):172-178. ${ }^{20}$ Copyright (C) 2018 Japanese Society of Allergology. Production and hosting by Elsevier B.V. All rights reserved. Creative Commons (CC BY-NC-ND 4.0; https:// creativecommons.org/licenses/by-nc-nd/4.0/legalcode).

If the diagnosis of asthma cannot be established, the diagnosis of ACO could be suggested by asthmatic traits, such as the presence of sputum or blood eosinophils $\geq 300$ cells/ $\mu \mathrm{L} .{ }^{16}$

\section{Epidemiology of ACO}

Both asthma and COPD are common diseases in adults. However, the prevalence of ACO is not well established.

The first observation is that the prevalence of ACO in patients with COPD varies widely according to the study design and definition used (Table 3). Population-based studies enrol a large number of individuals without the bias of predefined inclusion and exclusion criteria. However, due to the lack of data on reliable pulmonary function or other diagnostic tests, many population-based studies relied on a physician diagnosis or diagnostic codes only. Some of these studies may have overestimated the 


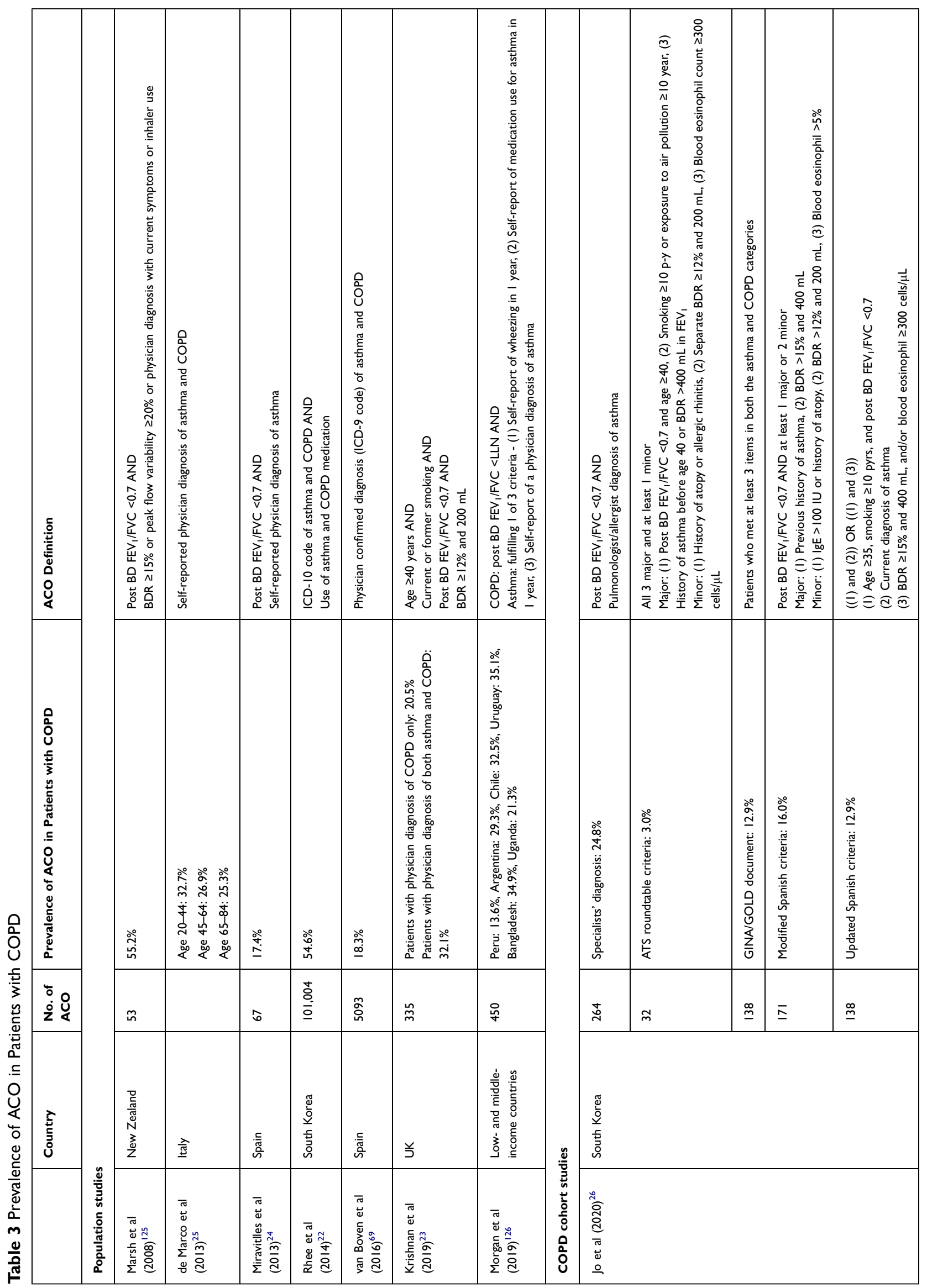




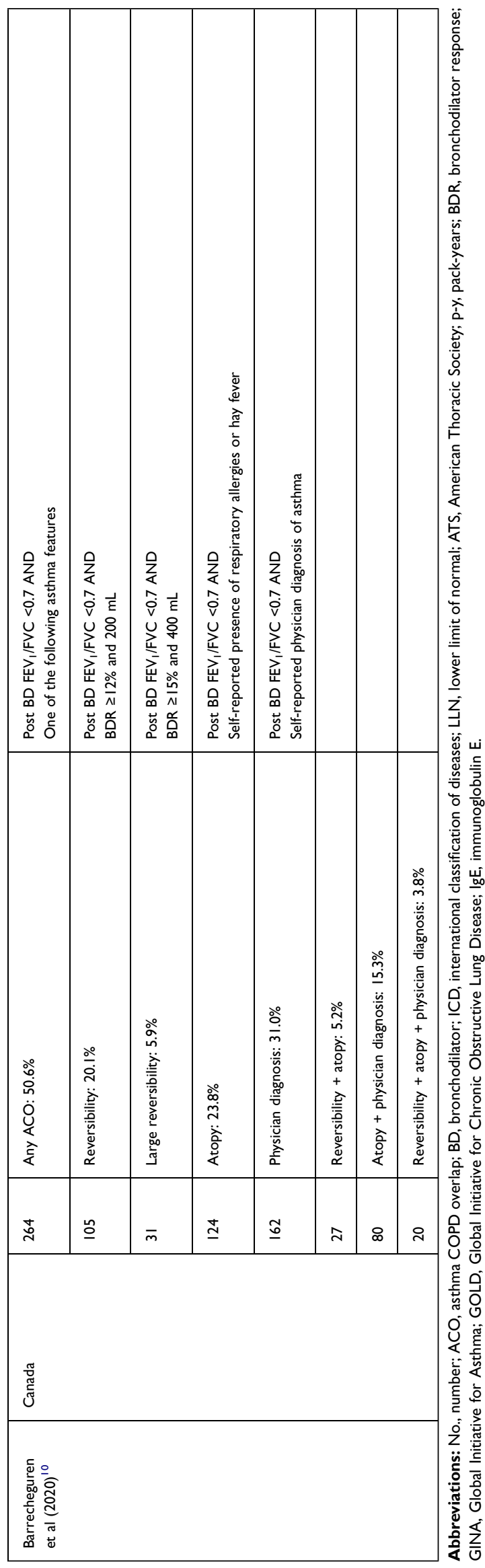

prevalence of ACO, as in a survey based on data from the Korean National Health Insurance Database in which 54\% of the 185,147 patients identified with COPD also had a diagnostic code for asthma. ${ }^{22}$ To overcome this problem, some population-based studies included standardised spirometry, but the number of participants was significantly reduced. As an example, Krishnan et $\mathrm{al}^{23}$ performed a study on 2165 adults with spirometry and a diagnosis of airways disease from the Optimum Patient Care Research Database (UK primary care database). They found a prevalence of ACO of $20.5 \%$ among patients with a diagnosis of COPD, $14 \%$ among those diagnosed with asthma and $32 \%$ among those with both clinical diagnoses of asthma and COPD. These results suggested that only one-third of patients with diagnostic codes for asthma and COPD have objective characteristics of ACO. Similar results have been found in other countries. A Spanish population-based study using post-bronchodilator spirometry found a prevalence of ACO of $17.4 \%$ among individuals with COPD. ${ }^{24}$ In an Italian study, the prevalence of ACO among COPD was $32.7 \%$ in subjects aged 20 to 44 years, $26.9 \%$ in those aged 45 to 64 years and $25.3 \%$ in ages $65-84$ years. The same study found a prevalence of ACO in the general Italian population of $1.6 \%$ (age 20-44), 2.1\% (age 45-64), and 4.5\% (age 65-84). ${ }^{25}$

In cohort studies, the prevalence of ACO can be measured more accurately than in population-based study, since data such as spirometry with bronchodilator reversibility and asthma features such as blood eosinophil counts, $\mathrm{IgE}$, and atopy, which are usually not fully available in population-based studies, may be available in cohort studies. However, cohort studies may not be representative of airway diseases in the general population because patients are usually enrolled in referral (or tertiary) hospitals. The prevalence of ACO among COPD patients in cohort studies is significantly lower than in population-based studies, but varies widely depending on the definition used. ${ }^{9,10,13}$ Jo et $\mathrm{al}^{26}$ found a prevalence of ACO according to various well-known definitions of between $3 \%$ and $24.7 \%$ among 1067 COPD patients from the KOCOSS cohort. Using CanCOLD data, Barrecheguren et $\mathrm{al}^{10}$ found a prevalence of ACO among COPD patients ranging from $3.8 \%$ to $50.6 \%$ according to seven different $\mathrm{ACO}$ criteria.

Prevalence of ACO has also been reported in patients with asthma. Milanese et $\mathrm{al}^{27}$ performed a survey on asthma patients aged $\geq 65$ and found a prevalence of ACO of $29 \%$ using the GINA-GOLD ACO definition. 
Forty-three percent of ACO patients were smokers or former smokers and interestingly $84 \%$ reported chronic bronchitis and 35\% demonstrated impaired DLCO. Kiljander et $\mathrm{al}^{28}$ investigated primary care asthma patients with a smoking history of at least 10 pack-years and found that $27.4 \%$ of these patients demonstrated irreversible airflow limitation and were diagnosed with ACO. This prevalence increased up to $37.8 \%$ in a population of 256 asthma patients from a tertiary referral hospital.

Recently, Hosseini et $\mathrm{al}^{29}$ performed a meta-analysis of 27 studies, which included population-based and cohort studies, in order to estimate the prevalence of ACO. Their results showed a prevalence of $2.0 \%$ (95\% confidence interval (CI) 1.4-2.6\%) among the general population, $26.5 \%$ (95\% CI 19.5-33.6\%) among asthma patients and 29.6\% (95\% CI 19.3-39.9\%) among COPD patients, but with substantial heterogeneity between studies.

In summary, the prevalence of ACO obtained from population-based studies can only be considered as indicative due to the lack of specific tests to reliably diagnose asthma features in patients with COPD. Although the prevalence of ACO in cohort studies may vary significantly according to the definition used and the methodology used to enrol participants, the most widely used definitions provide estimates of the prevalence of ACO of around $20 \%$ to $30 \%$, similarly among patients with COPD or asthma.

\section{Clinical Manifestations of ACO}

Studies that have reported on the clinical manifestations of ACO have focused on symptoms (most notably dyspnea), health-related quality of life, lung function, exercise intolerance, and exacerbations which are considered most relevant to patients and to physicians.

Most studies reported that ACO results in more severe symptoms than asthma or COPD alone, including a recent study that observed a higher disease burden for eosinophilic ACO compared with eosinophilic COPD or asthma. ${ }^{30}$ However, several individual trials and a systematic review suggested that this affirmation should be nuanced. ${ }^{31}$ Indeed, looking at each manifestation individually provides a better overview of the impact of ACO on patients. In terms of symptoms, it appears that patients with ACO experience more wheezing and mucus production than patients with asthma or COPD. ${ }^{32,33}$ Higher Medical Research Council (MRC) scores suggest that ACO patients also have more dyspnea ${ }^{24,25,27}$ with the three populations: asthma, COPD and ACO, otherwise being quite similar regarding symptoms.

Studies assessing lung function have mostly reported on FEV1 and FEV1 decline. Most of them show a lower FEV1 in ACO patients than in asthmatics, although similar values to that of COPD patients are found..$^{27,32,34-36}$ Regarding lung function decline, some small studies have not observed significant differences in the rate of decline of FEV1 between the asthma, COPD and ACO groups. ${ }^{32,33}$ However, a small Korean cohort study showed a slower decline of FEV1 for ACO compared to COPD over almost 6 years of follow-up (13.9 mL/year versus $29.3 \mathrm{~mL} /$ year; $\mathrm{p}=0.04) .{ }^{37}$ Similar results were reported by Lange et $\mathrm{al}^{38}$ using data from the Copenhagen City Heart Study with an FEV1 decline of $39.5 \mathrm{~mL} /$ year in COPD, compared with $27.3 \mathrm{~mL} /$ year in ACO patients with early onset asthma. However, patients with ACO based on late onset asthma had the worst prognosis with a decline of $49.6 \mathrm{~mL} /$ year $(\mathrm{p}=0.003) .{ }^{38}$ Though rarely investigated, DLCO appears similar in ACO and COPD patients, but is significantly reduced compared to asthmatic patients. ${ }^{12,14,39,40}$ Patients with ACO may have marked air trapping indicated by a higher residual volume compared to patients with asthma or COPD. ${ }^{10,39}$ Surprisingly, exercise capacity, which has been assessed using various methodologies in individual studies, does not appear to be significantly worse in patients with ACO than in those with asthma or COPD. ${ }^{35,41}$

Regarding exacerbations, a systematic review of eleven studies showed a significantly higher rate of exacerbations in ACO compared to asthma or COPD. ${ }^{31}$ A large epidemiological study in the US showed more hospitalisations and emergency department visits for ACO patients compared to COPD patients. ${ }^{42}$ Similarly, two large epidemiological studies in Spain and Latin America showed a significantly higher frequency of exacerbations in ACO compared to COPD patients. ${ }^{24,43}$ The Copenhagen City Heart Study demonstrated a significantly higher risk of severe exacerbations in ACO patients, especially in those associated with late onset asthma, compared with asthma or COPD alone. ${ }^{38}$ Finally, a Japanese study did not find poor clinical outcomes in patients with ACO receiving appropriate treatment. ${ }^{44}$

Clinical differences between ACO, asthma and COPD were more evident in the initial description of ACO cohorts compared with the more recent studies. ${ }^{22,45,46}$ Again, this difference may be due to differences in ACO definitions and methodology of the studies. ${ }^{9,10,47}$ The selection of asthma and COPD populations to which ACO is compared can also account for disparities amongst studies. Lastly, like asthma 
and $\mathrm{COPD}, \mathrm{ACO}$ is a heterogenous entity, whose clinical manifestations are expected to vary from one study to another. ${ }^{12,14,48}$ Refinement in the understanding of ACO and its underlying mechanisms will enable better appreciation of its differential clinical manifestations.

In conclusion, despite the differences in diagnostic criteria for ACO, the majority of studies have reported a high symptom burden associated with ACO, with a significantly higher frequency and severity of exacerbations compared with asthma and COPD.

\section{Genetics and Epigenetics of ACO}

Although the underlying genetic architecture of ACO remains largely a mystery, there are some emerging data to indicate the existence of specific chromosomal loci that may be responsible for this phenotype. The strongest evidence to date comes from the COPDGene study, which examined the genetic epidemiology of $\sim 10,000$ men and women 45 to 80 years of age, who had at least a 10 pack-year history of smoking. ${ }^{41}$ The subjects in the study were genotyped on the Illumina Human Omni Express array (Illumina, San Diego, CA, USA) with imputation based on the 1000 Genomes Phase I v3 European reference panel for the non-Hispanic whites and cosmopolitan reference panels for AfricanAmericans. This approach included over 6 million single nucleotide polymorphisms (SNPs) for the analysis. Of the 3570 subjects with GOLD 2 or greater severity of COPD (ie post-bronchodilator FEV1 $\leq 80 \%$ of predicted) in the COPDGene study, approximately $13 \%(\mathrm{~N}=450)$ had ACO, as defined by GOLD 2 or greater severity of COPD and a physician diagnosis of asthma before the age of 40 . The SNP that was most strongly related to ACO was within the CSMD1 gene on chromosome 8 ( $r$ 1179254; $p=1.57 \times 10^{-6}$ ) in non-Hispanic whites; whereas in the African-American population, it was rs2686829 (which is found on chromosome 7). If the ethnic groups were combined, many top hits were located on chromosome 14 near or within the gene GPR65. Other SNPs are shown in Table 4. Although the precise role of this protein is unknown in ACO, GPR65 is a member of the $\mathrm{G}$ protein-coupled receptor family and is expressed in activated eosinophils. Genetic knock-out of GPR65 has been shown to reduce levels of eosinophils in murine models of asthma. It should be noted, however, that none of the SNPs in the non-Hispanic whites, AfricanAmericans or the meta-analysis, met the genomic significance threshold of $\mathrm{p}<10^{-8}$. Interestingly, none of the known asthma SNPs or COPD SNPs were significantly enriched in the ACO population (Table 4).
Hansel et $\mathrm{al}^{49}$ examined another potential definition of ACO by evaluating the genetic architecture of airway hyperresponsiveness of COPD patients in the Lung Health Study (LHS). They genotyped 2814 non-Hispanic whites and related the underlying genetic structure of these participants with their level of airway responsiveness (as measured by a methacholine challenge test) at baseline and then at year 5 of follow-up. Although no SNPs reached the genetic threshold for statistical significance, 4 loci were identified that demonstrated nominal statistical significance (p-value between $10^{-4}$ and $10^{-7}$ ). None replicated and only 2 of the genes near these SNPs were lung expression quantitative trait loci (SGCD and MYH15).

Another phenotype of ACO is responsiveness to inhaled corticosteroids. This was examined in Lung Health Study-2, which was a randomized controlled trial to evaluate the therapeutic benefits of inhaled corticosteroids (ICS) (triamcinolone $1200 \mu \mathrm{g} / \mathrm{d}$ ) on the rate of FEV1 decline over 3 years in approximately 800 patients with COPD. Obeidat et $\mathrm{al}^{50}$ did not find any SNPs that reached genome-wide significance. However, there were 2 SNPs that significantly modified the effects of ICS on the rate of FEV1 decline, which were replicated in an external cohort, the Advair Biomarker in COPD trial, which was a shortterm randomized controlled trial that evaluated the effects of ICS on lung function in COPD patients.

Together, these data have elucidated promising genetic loci that may play a role in ACO. However, it should be noted that most studies to date have been underpowered to detect SNPs at a genome-wide significance level and replication of genetic "hits" has been lacking except for a few SNPs. Larger studies with improved phenotyping will be required to identify genes that are responsible for ACO.

\section{Biomarkers of ACO}

The lack of a strict ACO definition results in the need for biomarkers that could help in the identification of this phenotype. There is an increased awareness of the importance of recognizing ACO by using biomarkers. ${ }^{51}$ However, there are no biomarkers that can clearly differentiate ACO from asthma or COPD. ${ }^{52}$

Inflammation in COPD is predominantly mediated by T-helper cells (Th1), whereas in asthma T-helper cells (Th2) and type 2 innate lymphoid cells (ILC2) are key players in the inflammatory response. Th1 cells enhance cellmediated immunity and phagocyte-dependent inflammation through the production of interferon (IFN)- $\gamma$, interleukin (IL)-2, and tumour necrosis factor (TNF), while Th2 and 
Table 4 Different Single Nucleotide Polymorphisms (SNPs) Identified in Patients with ACO

\begin{tabular}{|c|c|c|c|}
\hline $\begin{array}{l}\text { How the "Asthmatic" Phenotype was } \\
\text { Defined in the Study }\end{array}$ & Study & $\begin{array}{l}\text { Promising SNPs, Nearest } \\
\text { Gene and p-value }\end{array}$ & $\begin{array}{l}\text { Replication in an } \\
\text { External Cohort }\end{array}$ \\
\hline Physician-diagnosis before age $40 \mathrm{yrs}^{41}$ & $\begin{array}{l}\text { COPDGene (non-Hispanic } \\
\text { whites) }\end{array}$ & $\begin{array}{l}\text { rsII779254, CSMDI }\left(10^{-6}\right) \\
\text { rs59569785, SOX5 }\left(10^{-6}\right) \\
\text { rsI0860I72, RMST }\left(10^{-6}\right) \\
\text { rs728I27I3, SEMA6A }\left(10^{-6}\right) \\
\text { rs429858I, ZDHHC2I }\left(10^{-6}\right)\end{array}$ & No \\
\hline Physician-diagnosis before age $40 \mathrm{yrs}^{41}$ & $\begin{array}{l}\text { COPDGene (African- } \\
\text { Americans) }\end{array}$ & $\begin{array}{l}\text { rs2686829, PKDILI }\left(10^{-7}\right) \\
\text { rs9577395, ATPIIA }\left(10^{-6}\right) \\
\text { rs386480I, REEP3 }\left(10^{-6}\right) \\
\text { rsI268I559, NRGI }\left(10^{-6}\right) \\
\text { rs28895885, AGA }\left(10^{-6}\right) \\
\text { rsII5905II8, KCNKI }\left(10^{-6}\right)\end{array}$ & No \\
\hline Airway hyper-reactivity ${ }^{49}$ & $\begin{array}{l}\text { Lung Health Study (non- } \\
\text { Hispanic whites) }\end{array}$ & $\begin{array}{l}\text { rs1049I678, LINGO2 }\left(10^{-6}\right) \\
\text { rs9486594, PDSS2 }\left(10^{-6}\right) \\
\text { rs76I83I4, RETNLB }\left(10^{-6}\right) \\
\text { rs2642660, SGCD }\left(10^{-4}\right)\end{array}$ & No \\
\hline Inhaled steroid response (FEVI decline) ${ }^{50}$ & $\begin{array}{l}\text { Lung Health Study (non- } \\
\text { Hispanic whites) }\end{array}$ & $\begin{array}{l}\text { rsIII720447, gene unknown } \\
\left(10^{-5}\right) \\
\text { rs } 10057473, \mathrm{NR} 3 \mathrm{CI}\left(10^{-2}\right)\end{array}$ & Yes \\
\hline
\end{tabular}

ILC2s produce IL-4, IL-5, IL-6, IL-9, IL-10, and IL-13, resulting in strong antibody responses and eosinophil accumulation, but inhibition of phagocyte-independent inflammation. The inflammatory pathways activated by both Th2 and ILC2 cells are collectively known as Type 2 inflammation. However, both COPD and asthma are heterogeneous diseases, and the two different inflammatory pathways may overlap in some patients, leading to a mixed inflammatory pattern.

Blood lymphocytes are usually low in ACO but are further reduced in COPD. ${ }^{53}$ It is suggested that IL-13 could be central to the regulation of inflammation in these conditions. $^{54}$ FeNO, blood eosinophils, and allergenspecific immunoglobulin $\mathrm{E}$ (IgE) are proposed for distinguishing between asthma and COPD. ${ }^{6}$ Although the addition of serum IgE does not clearly improve the clinical definition of ACO, it could be used to subdivide individuals with atopic and non-atopic ACO, who might have different biologic mechanisms and potential treatments. ${ }^{55}$ Inflammation in asthma predominantly involves eosinophils, whereas in COPD it is characterized by neutrophils. ${ }^{5,56}$ FENO and eosinophils suggest local and systemic eosinophilic inflammation, which is suggestive of asthma, ${ }^{57,58}$ as well as markers of atopy such as total serum IgE and antigen-specific IgE levels. ${ }^{59}$ These inflammatory biomarkers could be used to support the diagnosis of ACO in a patient with COPD. ${ }^{60}$ In this respect, the cut-off for high blood eosinophil count in COPD to identify a Type 2 predominant inflammation is still under discussion, but most studies suggest $\geq 300$ cells $/ \mu \mathrm{L} .{ }^{61}$ Serum periostin is high in patients with ACO as well in those with asthma but not in patients with COPD, whereas serum YKL-40 is high in both patients with ACO and COPD, but not in asthma. ${ }^{62}$ These results suggest that ACO has both pathogeneses of asthma and COPD leading to high expression of periostin (a surrogate marker of IL-13 activity and Type 2 inflammation) and YKL-40 (non-Type 2 inflammation) and combined assessment of serum periostin and YKL40 could help in the diagnosis of ACO.

The serum levels of IL-9, vascular endothelial growth factor A (VEGFA) and placental growth factor (PIGF) in patients with ACO are significantly higher than in nonACO asthmatics, while the levels of IL-8 and IL-17A are lower in ACO compared to asthmatics. ${ }^{63}$

Recently, it was reported that 11 metabolites: serine, threonine, ethanolamine, glucose, cholesterol, 2-palmitoylglycerol, stearic acid, lactic acid, linoleic acid, D-mannose, and succinic acid, were found to be significantly altered in ACO as compared with asthma or COPD. ${ }^{64}$ This provides novel insights into metabolic pathways and inflammatory mediators involved in the mechanisms underlying ACO and how these 
processes may be linked to each other and also with the pulmonary function impairment. Lastly, there are epigenetic changes showing a characteristic expression profile of miRNAs in ACO, distinctive from asthma and COPD. ${ }^{65,66}$

The different inflammatory mechanisms involved in asthma and COPD may overlap in certain patients, but so far, no single biomarker or combination of biomarkers can be used to accurately identify ACO. Blood eosinophils, FeNO and periostin are readily available to identify the T2 inflammation in COPD patients. Recent studies suggest that a set of interleukins could be useful to detect a mixed inflammatory pattern (T2 and non-T2) with a high degree of certainty (Figure 1). It is uncertain, however, whether these new biomarkers may provide better diagnostic accuracy for ACO compared with the traditional $\mathrm{T} 2$ biomarkers or if they may play a role in the future for the identification of ACO in clinical practice. Moreover, their reproducibility is uncertain and is yet to be proven or specified, ie some biomarkers like blood eosinophil count may require repeated measures.

\section{Prognosis of $\mathrm{ACO}$}

The long-term outcomes of ACO patients in terms of survival have been explored in both population-based and cohort studies with conflicting results. Most population-based studies have reported increased mortality in patients with $\mathrm{ACO}$, probably due to the defining criteria of the coexistence of both diagnoses, asthma and COPD, that is usually associated with more clinical visits and higher severity. In contrast, most cohort studies show lower mortality in ACO than in COPD, probably due to the better response of these patients to medical treatment compared to COPD alone. Regarding population-based studies, Kumbhare et al $^{67}$ investigated mortality among patients with obstructive lung disease, based on selfreported diagnoses of asthma, COPD and ACO, compared to the US general population. The ACO group was younger and had a higher proportion of ex-smokers than the group with COPD. Mortality rates from cardiovascular disease and malignancy were similar across the disease categories, but ACO patients had a disproportionately higher number of deaths from chronic respiratory disease compared to the other groups, although this was not statistically significant compared to COPD after adjusting for age, sex and smoking status. Similar results were observed by Baarnes et $\mathrm{al}^{68}$ in a population of over 57,000 adults aged 50-64 years. ACO $(n=662)$ was defined as at least one hospital admission for asthma and one for COPD at different time points. All-cause mortality was found to be

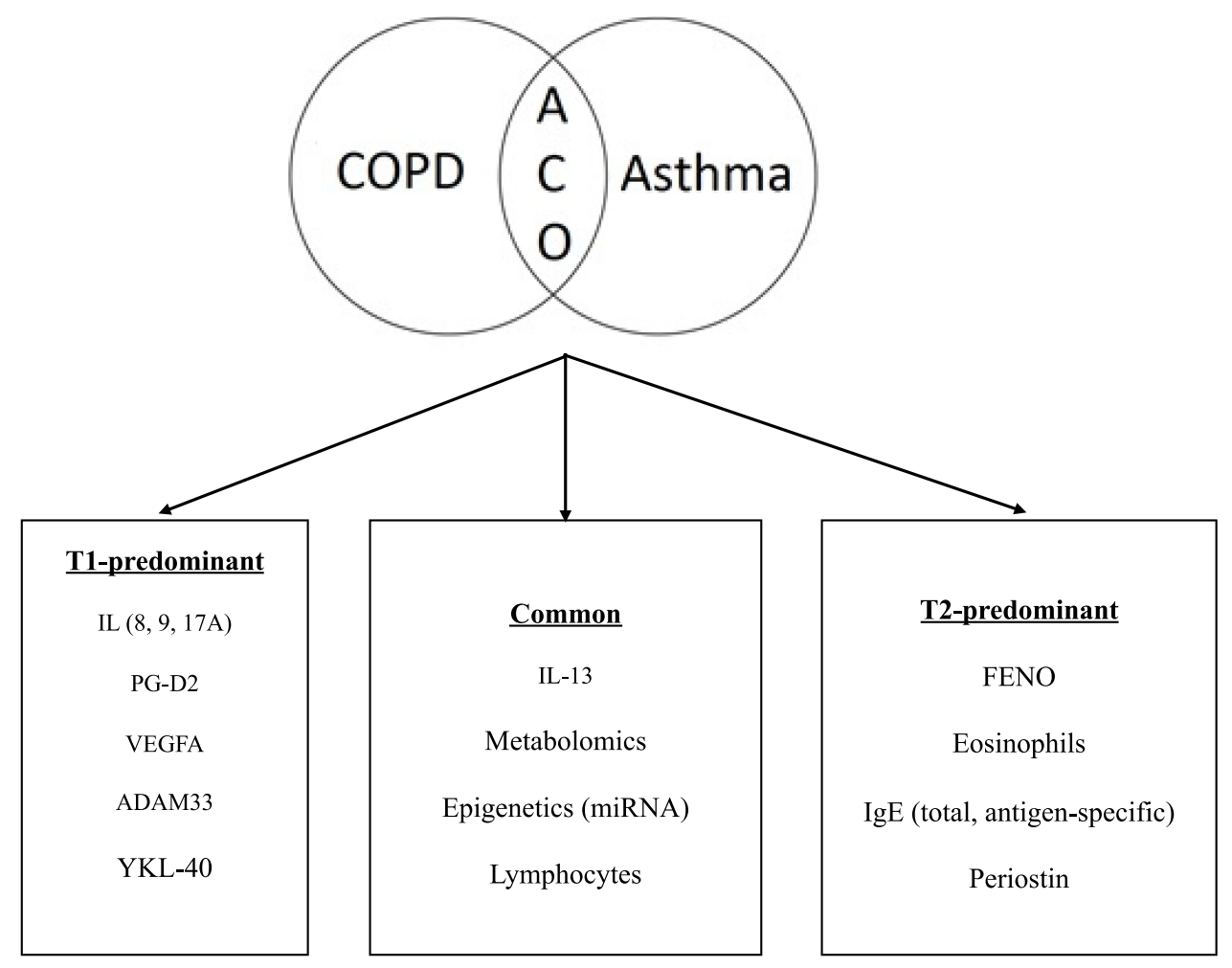

Figure I Proposed biomarkers for differentiating ACO from asthma and COPD. 
significantly higher among participants with ACO compared to either asthma or COPD alone, especially among women and younger participants. Finally, in a large epidemiological study in Denmark with 8382 participants, patients with ACO associated with late onset asthma had the worst survival with a reduced life expectancy of 12.8 years compared with healthy never-smokers, which was significantly worse than the 10.1 years of reduced survival of COPD and 3.3 years of asthma patients. Patients with ACO associated with early onset asthma had a similar survival compared with COPD (9.3 years reduction in survival). ${ }^{38}$

In contrast, the cohort studies provide contradictory results in terms of survival for patients classified as ACO. A multicenter, prospective study of 831 patients with obstructive lung disease showed a one-year survival rate of $94.7 \%$ for ACO compared with $87.3 \%$ for COPD $(p<0.05) .{ }^{69}$ Another retrospective, observational study of 891 COPD patients classified according to the Spanish COPD guidelines into ACO, non-exacerbators, exacerbators with chronic bronchitis and exacerbators with emphysema. Golpe et $\mathrm{al}^{70}$ found that ACO patients had the best long-term prognosis compared to the three other phenotypes of COPD. However, no significant differences in mortality were found after adjusting for potential confounders, suggesting that the observations were primarily driven by between-group differences in COPD severity and co-morbidities.

A retrospective, 10-year follow-up study of 214 patients hospitalized with an exacerbation of COPD reported that ACO patients had a significantly better survival than patients with COPD alone (mean survival $4.7 \mathrm{vs}$ 1.7 years, $\mathrm{p}=0.001) .{ }^{71}$ Poor lung function was associated with poor survival in both groups, but the prognosis was still significantly better in ACO patients irrespective of whether the FEV1 was over or under of $50 \%$ predicted. However, patients with higher BMI ( $>25)$ seemed to have a trend for better survival $(p=0.055)$, but no differences were found between ACO and COPD groups. This "obesity paradox" has been documented before in patients with COPD and appears to be valid also in patients with ACO. Another study evaluated 15-year mortality in 1065 individuals older than 65 years of age in Italy, ${ }^{72}$ and reported a significantly higher risk of death in individuals with ACO compared to controls (Hazard Ratio $(\mathrm{HR})=1.82$ ), but even higher for COPD $(\mathrm{HR}=2.12)$ after adjusting for age, sex and tobacco exposure.
In a study of 65 patients with ACO, defined as COPD plus a positive bronchodilator test, versus 65 patients with COPD and a negative bronchodilator test, Bai et $\mathrm{al}^{73}$ reported a significantly lower mortality in ACO patients compared to COPD. However, this difference may at least partly be explained by ACO patients having a more preserved diffusion capacity compared to COPD only (DLCO $71 \%$ predicted vs $56 \%$ predicted, $\mathrm{p}<0.001)$. Similarly, Suzuki et $\mathrm{al}^{74}$ in the Hokkaido cohort demonstrated a significantly reduced 10 -year mortality in patients with COPD who had at least two of the so-called asthma-like features (positive bronchodilator test, increased blood eosinophils and/or atopy), compared with COPD patients with 0 or 1 of these features.

The reported findings from the majority of cohort studies suggest that the risk of death of ACO patients is significantly reduced compared with COPD, but not compared with asthma. This may be due to the different characteristics of ACO patients such as less severe emphysema, but also due to better response to some widely used pharmacological therapies, not least inhaled corticosteroids.

\section{Treatment of ACO}

Very few clinical trials have evaluated the efficacy of therapy in ACO; generally, these patients are excluded from clinical trials of COPD or asthma; furthermore, there is a lack of regulatory definition of ACO. Yet, patients with ACO that would possibly benefit from these treatments are encountered frequently in clinical practice. Currently, decisions regarding therapy in these patients should be guided based on phenotypical data and severity of symptoms, taking into account whether asthma or COPD is most pronounced in the individual ACO patient, even in mild stages of the disease. ${ }^{75}$ Next, a stepwise approach similar to the algorithms for the treatment of asthma or COPD must be followed according to the severity of symptoms (Figure 2). ${ }^{8,21}$ For patients with milder forms of asthma inhaled therapy comprising of ICS is adequate, while symptomatic COPD patients are treated with long-acting bronchodilators. Yet, there is a key difference; the treatment algorithms recommend that ICS should be introduced earlier in asthma and in COPD patients with a history of exacerbations and/or increased blood eosinophils. ${ }^{8,21}$ ICS improves asthma outcomes with regard to exacerbations, control of symptoms and lung function. ${ }^{76,77}$ Importantly, long-acting beta-2 agonists (LABA) have been associated with an increased 


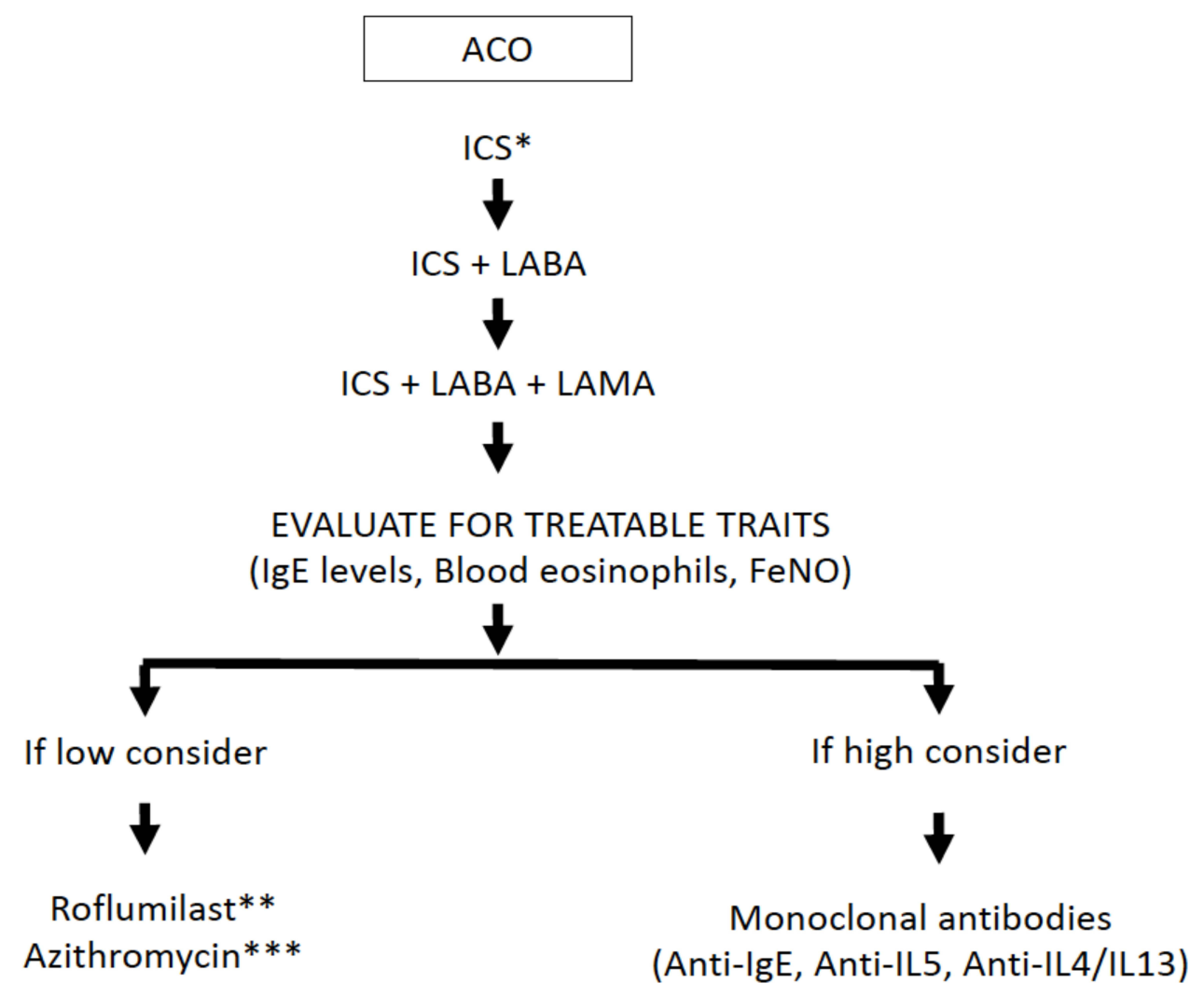

Figure 2 Treatment algorithm for ACO.

Notes: *Due to risk in asthmatics with LABA monotherapy, ICS is the preferred therapy in ACO. **For patients with a chronic bronchitis phenotype and a FEVI < $50 \%$. ****For ex-smokers and infective exacerbations.

Abbreviations: ACO, asthma COPD overlap; FeNO, exhaled nitric oxide; ICS, inhaled corticosteroids; IgE, immunoglobulin E; IL, interleukin; LABA, long-acting beta agonist; LAMA, long-acting muscarinic antagonist.

risk of asthma-related death when not given in combination with an ICS and should not be prescribed as a single therapy in asthma. ${ }^{78,79}$ Given this risk, it is recommended that a LABA should always be prescribed in conjunction with ICS in patients with ACO ${ }^{80}$ Furthermore, studies have shown that in ACO patients the use of ICS/LABA appears to be safe and effective. ${ }^{81}$ There is no evidence of the efficacy and safety of the use of PRN ICS/formoterol for relief of symptoms on top of maintenance treatment in ACO patients; however, this appears to be a reasonable option since a long-acting bronchodilator with a quick onset of action may be effective in symptoms control and these patients respond well to ICS. The initiation of a short course of ICS/LABA in patients with COPD at the onset of a lower respiratory tract infection has been shown to reduce the risk of severe exacerbations. ${ }^{82}$ Leukotriene receptor antagonists have not been demonstrated to be effective in COPD; however, they may be used in ACO patients with the phenotype of smoking asthmatic. ${ }^{80}$

The combination of ICS/LABA/long-acting muscarinic antagonist (LAMA) (ie triple therapy) has been effective in asthma by improving lung function and in COPD by reducing exacerbations versus ICS/LABA. ${ }^{83-89}$ Therefore, if a patient with $\mathrm{ACO}$ is not adequately controlled with a combination of an ICS/LABA, then a LAMA should be considered as an adjunctive therapy, particularly in the setting of recurrent exacerbations. Although small studies have supported the use of triple therapy in ACO, larger, more definitive, studies are still required to confirm the benefit and safety of this strategy in this patient population. $^{90}$

If an ACO patient remains uncontrolled despite maximal inhaler therapy, other treatment options may be considered. Roflumilast is an oral phosphodiesterase 4 inhibitor that is effective in preventing exacerbations in patients with COPD and chronic bronchitis. Some studies have observed that roflumilast may be more effective in COPD patients with high blood eosinophils. ${ }^{91}$ On the other hand, roflumilast has been demonstrated to be effective in asthma,${ }^{92,93}$ therefore, it is likely that ACO patients with chronic cough and sputum production may benefit from this treatment for prevention of exacerbations. ${ }^{91}$ Another 
possible treatment is montelukast, with very limited efficacy in COPD, but has demonstrated to improve asthma control in smoking asthmatics. ${ }^{94}$

In patients with moderate-to-severe asthma, monoclonal antibodies that target T2 inflammatory cytokines have been shown to decrease exacerbations and corticosteroid requirements and improve lung function and quality of life. ${ }^{95-99}$ These targeted therapies have been studied in COPD with mixed results. A study evaluated the response to omalizumab, a monoclonal antibody that targets immunoglobulin E, in patients with ACO compared to those with asthma alone. ${ }^{100}$ Participants were assessed at baseline and after 6 months of therapy and both groups demonstrated improvements in symptom control and quality of life. Another study evaluated the efficacy of omalizumab over 48 weeks of therapy and reported similar improvements in exacerbation rate and symptom control in subjects with ACO or asthma alone. ${ }^{101}$ Mepolizumab, a monoclonal antibody directed against IL-5, has been tested in two Phase III, placebocontrolled, double-blind, randomized, multinational trials (METREX and METREO) in COPD patients on triple therapy and varying levels of blood eosinophils. ${ }^{102}$ Only one of the trials (METREX) reached the primary endpoint of significant reduction of exacerbations after 52 weeks of mepolizumab vs placebo (1.40 vs 1.71 per year; rate ratio 0.82 ; $95 \%$ CI, 0.68-0.98; $\mathrm{P}=0.04$ ) in patients with an eosinophilic phenotype. There were no improvements in the SGRQ or CAT score in either trial. ${ }^{102}$ Finally, the use of benralizumab, an IL-5 receptor alpha-directed cytolytic monoclonal antibody, did not improve the rates of exacerbations in two phase III, randomized, placebo-controlled trials that included patients with moderate to severe COPD with eosinophilic phenotype and a history of exacerbations. ${ }^{103}$ Yet, a subgroup analysis revealed that benralizumab reduced exacerbations in those patients who, on top of an eosinophilic phenotype, also had three or more exacerbations in the past year, impaired lung function (ie post-bronchodilator FEV1 $<40 \%$ ) and significant bronchodilator response (ie $>15 \%$ ). ${ }^{104}$ Altogether, these findings suggest that $\mathrm{T} 2$ targeted therapies may be beneficial in a subgroup of patients with COPD, particularly those that have features of asthma. Thus, these therapies should not be withheld in patients with ACO.

Chronic therapy with azithromycin has been shown to reduce exacerbations in both asthma and COPD. ${ }^{105-108}$ Careful consideration of risks and benefits is recommended before starting this therapy in chronic airway diseases. ${ }^{8,21}$ For ACO patients, chronic therapy with azithromycin may be considered, particularly in those patients that have frequent exacerbations and are not candidates for other therapies. ${ }^{80}$

\section{ACO in Clinical Practice Guidelines}

As early as 2007, the Canadian guidelines for COPD recognised that some patients with COPD may have an asthma component and may require different treatments, in particular an early introduction of ICS. ${ }^{4}$ Three years later, in 2010, the Japanese guidelines on COPD included a chapter on "COPD complicated by asthma" which also recommended the early introduction of ICS in these patients. $^{109}$ These two documents did not include a precise definition of the overlap between COPD and asthma; they only indicated that characteristics of both diseases may coexist in some patients and that this could have implications for treatment. One of the first national guidelines to introduce the term ACO was the Spanish COPD guidelines in $2012 ;^{110}$ and for the first time, this document included a consensus definition of ACO. ${ }^{111}$ Interestingly, a few years later, the Czech, ${ }^{112}$ the Finnish, ${ }^{113}$ the Middle East-North Africa Region, ${ }^{114}$ and the latest update of the Japanese COPD guidelines ${ }^{20}$ adopted the same approach, with few modifications, in their documents.

A crucial time in the acceptance of ACO by the medical community was the publication in 2014 of the joint document by GINA-GOLD. This document presented a list of characteristics that identify COPD or asthma and the coexistence of a similar number of traits for both diseases in an individual patient was suggested as a diagnostic of ACO. ${ }^{6}$

The initial criteria for ACO included a series of clinical and biological variables that were difficult to apply in clinical practice. With the advancing knowledge on the relevant characteristics of this phenotype it was possible to simplify the criteria and the new Spanish consensus included the two main types of patients with ACO: COPD with coexistent asthma and eosinophilic COPD. ${ }^{16,115}$ It was recognised that these two types of patients were different, but they were grouped together under the umbrella term of ACO because the therapeutic approach was the same. ${ }^{116}$ Other guidelines, such as the Portuguese guideline on COPD, have followed a similar approach. ${ }^{117}$

However, after the publication of the joint GINAGOLD statement on ACO in 2014, the following updates of the GOLD document did not explicitly include the concept of ACO in their recommendations for 
management. Moreover, the 2020 update indicates that GOLD will no longer refer to ACO, but GOLD recommends the use of blood eosinophil counts to direct the therapy with ICS in COPD. ${ }^{8}$ In contrast, GINA 2020 refers to ACO or "asthma + COPD" as simple descriptors for patients who have features of both asthma and COPD and emphasises that these terms do not refer to a single disease entity. On the contrary, they include patients with several clinical phenotypes that are likely caused by a range of different underlying mechanisms. ${ }^{118}$ The use of blood eosinophil counts to guide ICS therapy has been included in the new Canadian, ${ }^{119}$ Spanish $^{120}$ and Latin American guidelines for COPD ${ }^{121}$ and in the European Respiratory Society guidelines for ICS withdrawal. ${ }^{122}$ It appears that the tendency for the future will be to differentiate the phenotype of eosinophilic COPD, based on blood eosinophil counts and leave the concept of ACO for patients who fulfil the diagnostic criteria for both asthma and COPD simultaneously irrespective of blood eosinophil counts.

\section{Conclusions}

In conclusion, despite disagreement on the definition and recognition of ACO as a distinct pathophysiological entity, ${ }^{123,124}$ most clinicians and scientists agree that the current definitions of asthma and COPD misclassify a subgroup of patients with a different phenotype in terms of clinical presentation and, most importantly, in terms of clinical course. This is important because an appropriate identification of ACO patients may allow better-targeted therapy, and hopefully, improved clinical course, much like is currently done in asthma and COPD. Hence, this subgroup of patients deserves attention in order to be appropriately identified for further mechanistic studies, and to enable individualized management.

\section{Disclosure}

Evgeni Mekov has received grants and personal fees from Chiesi, and speaker or consulting fees from Astra Zeneca and Chiesi. Alexa Nuñez is the recipient of a Rio Hortega contract in the 2019 Strategic Action Health Call from the Instituto de Salud Carlos III for the years 2020-2022. Don D. Sin has received honoraria for speaking engagements on COPD topics from AstraZeneca, Boehringer Ingelheim and has sat on advisory boards of AZ, Grifols and Nuvaira. Masakazu Ichinose has received honoraria for speaking from AstraZeneca, Nippon Boehringer Ingelheim, Kyorin and Novartis Pharma. Chin Kook Rhee reports personal fees from MSD and consulting/lecture fees from AstraZeneca, GSK, Novartis, Takeda, Mundipharma, Boehringer-Ingelheim, Teva, Sanofi, and Bayer, outside the submitted work. Diego Jose Maselli reports personal fees from GlaxoSmithKline, AstraZeneca and Sanofi Regeneron GSK, Genentech, and Sunovion, during the conduct of the study. Andréanne Coté reports grants from GlaxoSmithKline personal fees from Sanofi Regeneron, and consulting and speaker fees on asthma topics from AstraZeneca, GlaxoSmithKline and Sanofi. Charlotte Suppli Ulrik has received speaker fees and/or research grants from AstraZeneca, GSK, Boehringer-Ingelheim, Chiesi, TEVA, Mundipharma, Sandoz, Actelion, Orion Pharma, Novartis, Sanofi Genzyme and ALK-Abello and has been on advisory boards for AstraZeneca, GSK, Boehringer-Ingelheim, Chiesi, Novartis, Sanofi Genzyme and TEVA. Francois Maltais reports grants from AstraZeneca, GlaxoSmithKline, Boehringer Ingelheim, GSK, Sanofi, Grifols, and Novartis, and personal fees for serving on speaker bureaus and consultation panels from GlaxoSmithKline, Boehringer Ingelheim, Grifols, and Novartis; he is financially involved with Oxynov, a company which is developing an oxygen delivery system. Antonio Anzueto has received consultant fees from AstraZeneca, Boehringer Ingelheim, Grifols; GlaxoSmithKline, Verona Pharma, TEVA, Mylan/ Theravance. Marc Miravitlles has received speaker/personal fees from AstraZeneca, Boehringer Ingelheim, Chiesi, Cipla, Menarini, Rovi, Bial, Sandoz, Zambon, CSL Behring, Grifols and Novartis, consulting fees from AstraZeneca, Boehringer Ingelheim, Chiesi, GlaxoSmithKline, Bial, Gebro Pharma, Kamada, CSL Behring, Laboratorios Esteve, Ferrer, Mereo Biopharma, Verona Pharma, TEVA, Spin Therapeutics, pH Pharma, Novartis, Sanofi and Grifols and research grants from Grifols. The authors reported no other potential conflicts of interest for this work.

\section{References}

1. Christenson SA, Steiling K, van den Berge M, et al. Asthma-COPD overlap: clinical relevance of genomic signatures of type 2 inflammation in COPD. Am J Respir Crit Care Med. 2015;191:758-766. doi:10.1164/rccm.201408-1458OC

2. Barrecheguren M, Esquinas C, Miravitlles M. The asthma COPD overlap syndrome (ACOS). Opportunities and challenges. Curr Opin Pulm Med. 2015;21:74-79. doi:10.1097/ MCP.0000000000000118

3. Orie NGM, Sluiter HJ, eds. Bronchitis. Assen, the Netherlands: Royal van Gorcum; 1962.

4. O'Donnell DE, Aaron S, Bourbeau J, et al. Canadian Thoracic Society recommendations for management of chronic obstructive pulmonary disease 2007 update. Can Respir J. 2007;14(Suppl B):5B-32B. doi:10.1155/2007/830570 
5. Gibson PG, Simpson JL. The overlap syndrome of asthma and COPD: what are its features and how important is it? Thorax. 2009;64:728-735. doi:10.1136/thx.2008.108027

6. GINA-GOLD diagnosis of disease of chronic airflow limitation: asthma, COPD and asthma-COPD overlap syndrome (ACOS). Available from: https://goldcopd.org/asthma-copd-asthma-copd-over lap-syndrome/. Accessed November 25, 2020.

7. Barnes PJ. Asthma-COPD overlap. Chest. 2016;149(1):7-8. doi:10.1016/j.chest.2015.08.017

8. Global Initiative for Chronic Obstructive Lung Disease (GOLD). Global strategy for the diagnosis, management and prevention of COPD. 2020 Report; 2020. Available from: https://goldcopd.org/ wp-content/uploads/2019/12/GOLD-2020-FINAL-ver1. 2-03Dec19_WMV.pdf. Accessed November 25, 2020.

9. Bonten $\mathrm{TN}$, Kasteleyn MJ, de Mutsert R, et al. Defining asthma-COPD overlap syndrome: a population-based study. Eur Respir J. 2017;49(5):1602008. doi:10.1183/13993003.020082016

10. Barrecheguren M, Pinto L, Mostafavi-Pour-Manshadi SM, et al. Identification and definition of asthma-COPD overlap: the CanCOLD study. Respirology. 2020;25(8):836-849. doi:10.1111/ resp. 13780

11. Nuñez A, Sarasate M, Loeb E, et al. Practical guide to the identification and diagnosis of asthma-COPD overlap (ACO). COPD. 2019;16:1-7. doi:10.1080/15412555.2019.1575802

12. Boulet LP, Boulay MÈ, Dérival JL, et al. Asthma-COPD overlap phenotypes and smoking: comparative features of asthma in smoking or non-smoking patients with an incomplete reversibility of airway obstruction. COPD. 2018;15(2):130-138. doi:10.1080/ 15412555.2017.1395834

13. Soler-Cataluña JJ, Novella L, Soler C, et al. Clinical characteristics and risk of exacerbations associated with different diagnostic criteria of asthma-COPD overlap. Arch Bronconeumol. 2020;56(5):282-290. doi:10.1016/j.arbres.2019.08.023

14. Tommola M, Ilmarinen P, Tuomisto LE, et al. Differences between asthma-COPD overlap syndrome and adult-onset asthma. Eur Respir J. 2017;49(5):1602383. doi:10.1183/ 13993003.02383-2016

15. Sin DD, Miravitlles $M$, Mannino DM, et al. What is asthma-COPD overlap syndrome (ACOS)? Towards a consensus definition from a roundtable discussion. Eur Respir J. 2016;48:664-673. doi:10.1183/13993003.00436-2016

16. Miravitlles M, Alvarez-Gutierrez FJ, Calle M, et al. Algorithm for identification of asthma-COPD overlap: consensus between the Spanish COPD and asthma guidelines. Eur Respir J. 2017;49 (5):1700068. doi:10.1183/13993003.00068-2017

17. Matsunaga K, Kuwahira I, Hanaoka M, et al. An official JRS statement: the principles of fractional exhaled nitric oxide (FeNO) measurement and interpretation of the results in clinical practice. Respir Investig. 2021;59(1):34-52. doi:10.1016/j.resinv.2020.05.006

18. Mostafavi-Pour-Manshadi SM, Naderi N, Barrecheguren M, et al. Investigating fractional exhaled nitric oxide in chronic obstructive pulmonary disease (COPD) and asthma-COPD overlap (ACO): a scoping review. COPD. 2018;15(4):377-391. doi:10.1080/ 15412555.2018.1485637

19. Japanese Respiratory Society (JRS). Definition and diagnosis of asthma-COPD overlap (ACO), the JRS guidance for the management of ACO 2018. Tokyo: Medical Review; 2017.

20. Yanagisawa S, Ichinose $M$. Definition and diagnosis of asthma-COPD overlap (ACO). Allergol Int. 2018;67 (2):172-178. doi:10.1016/j.alit.2018.01.002

21. Global Initiative for Asthma. Global strategy for asthma management and prevention; Updated 2017. Available from: http:// ginasthma.org/2017-gina-report-globalstrategy-for-asthmamanagement-andprevention/. Accessed November 25, 2020.
22. Rhee CK, Yoon HK, Yoo KH, et al. Medical utilization and cost in patients with overlap syndrome of chronic obstructive pulmonary disease and asthma. COPD. 2014;11(2):163-170. doi:10.3109/15412555.2013.831061

23. Krishnan JA, Nibber A, Chisholm A, et al. Prevalence and characteristics of asthma-chronic obstructive pulmonary disease overlap in routine primary care practices. Ann Am Thorac Soc. 2019;16(9):1143-1150. doi:10.1513/AnnalsATS.201809-607OC

24. Miravitlles M, Soriano JB, Ancochea J, et al. Characterisation of the overlap COPD-asthma phenotype. Focus on physical activity and health status. Respir Med. 2013;107(7):1053-1060. doi:10.1016/j.rmed.2013.03.007

25. de Marco R, Pesce G, Marcon A, et al. The coexistence of asthma and chronic obstructive pulmonary disease (COPD): prevalence and risk factors in young, middle-aged and elderly people from the general population. PLoS One. 2013;8(5):e62985. doi:10.1371/journal.pone.0062985

26. Jo YS, Hwang YI, Yoo KH, et al. Effect of inhaled corticosteroids on exacerbation of asthma-COPD overlap according to different diagnostic criteria. J Allergy Clin Immunol Pract. 2020;8 (5):1625-1633 e1626. doi:10.1016/j.jaip.2020.01.004

27. Milanese M, Di Marco F, Corsico AG, et al. Asthma control in elderly asthmatics. An Italian observational study. Respir Med. 2014;108(8):1091-1099. doi:10.1016/j.rmed.2014.05.016

28. Kiljander T, Helin T, Venho K, et al. Prevalence of asthma-COPD overlap syndrome among primary care asthmatics with a smoking history: a cross-sectional study. NPJ Prim Care Respir Med. 2015;25:15047. doi:10.1038/npjpcrm.2015.47

29. Hosseini M, Almasi-Hashiani A, Sepidarkish M, et al. Global prevalence of asthma-COPD overlap (ACO) in the general population: a systematic review and meta-analysis. Respir Res. 2019;20(1):229. doi:10.1186/s12931-019-1198-4

30. Hiles SA, Gibson PG, McDonald VM. Disease burden of eosinophilic airway disease: comparing severe asthma, COPD and asthma-COPD overlap. Respirology. 2021;26(1):52-61. doi:10.1111/resp.13841

31. Nielsen M, Bårnes CB, Ulrik CS. Clinical characteristics of the asthma-COPD overlap syndrome-a systematic review. Int J Chron Obstruct Pulmon Dis. 2015;10:1443-1454. doi: $10.2147 /$ COPD.S85363

32. Brzostek D, Kokot M. Asthma-chronic obstructive pulmonary disease overlap syndrome in Poland. Findings of an epidemiological study. Postepy Dermatol Alergol. 2014;31(6):372-379. doi: 10.5114 pdia.2014.47120

33. Pleasants RA, Ohar JA, Croft JB, et al. Chronic obstructive pulmonary disease and asthma-patient characteristics and health impairment. COPD. 2014;11(3):256-266. doi:10.3109/15412555.2013.840571

34. Kauppi P, Kupiainen H, Lindqvist A, et al. Overlap syndrome of asthma and COPD predicts low quality of life. J Asthma. 2011;48 (3):279-285. doi:10.3109/02770903.2011.555576

35. Fu JJ, Gibson PG, Simpson JL, et al. Longitudinal changes in clinical outcomes in older patients with asthma, COPD and asthma-COPD overlap syndrome. Respiration. 2014;87 (1):63-74. doi:10.1159/000352053

36. Lee H, Kim SH, Kim BK, et al. Characteristics of Specialist-Diagnosed Asthma-COPD Overlap in Severe Asthma: observations from the Korean Severe Asthma Registry (KoSAR). Allergy. 2021;76(1):223-232. doi:10.1111/all.14483

37. Park HY, Lee SY, Kang D, et al. Favorable longitudinal change of lung function in patients with asthma-COPD overlap from a COPD cohort. Respir Res. 2018;19(1):36. doi:10.1186/s12931-018-0737-8

38. Lange P, Çolak Y, Ingebrigtsen TS, et al. Long-term prognosis of asthma, chronic obstructive pulmonary disease, and asthma-chronic obstructive pulmonary disease overlap in the Copenhagen City Heart study: a prospective population-based analysis. Lancet Respir Med. 2016;4(6):454-462. doi:10.1016/ S2213-2600(16)00098-9 
39. Lee HY, Kang JY, Yoon HK, et al. Clinical characteristics of asthma combined with COPD feature. Yonsei Med J. 2014;55 (4):980-986. doi:10.3349/ymj.2014.55.4.980

40. Kitaguchi Y, Yasuo M, Hanaoka M. Comparison of pulmonary function in patients with COPD, asthma-COPD overlap syndrome, and asthma with airflow limitation. Int J Chron Obstruct Pulmon Dis. 2016;11:991-997. doi:10.2147/COPD.S105988

41. Hardin M, Cho M, McDonald ML, et al. The clinical and genetic features of COPD-asthma overlap syndrome. Eur Respir J. 2014;44(2):341-350. doi:10.1183/09031936.00216013

42. Kumbhare S, Pleasants R, Ohar JA, et al. Characteristics and Prevalence of Asthma/Chronic Obstructive Pulmonary Disease Overlap in the United States. Ann Am Thorac Soc. 2016;13 (6):803-810. doi:10.1513/AnnalsATS.201508-554OC

43. Menezes AMB, Montes de Oca M, Pérez-Padilla R, et al. Increased risk of exacerbation and hospitalization in subjects with an overlap phenotype: COPD-asthma. Chest. 2014;145 (2):297-304. doi:10.1378/chest.13-0622

44. Kobayashi S, Hanagama M, Ishida $M$, et al. Clinical Characteristics and Outcomes of Patients with Asthma-COPD Overlap in Japanese Patients with COPD. Int J Chron Obstruct Pulmon Dis. 2020;15:2923-2929. doi:10.2147/COPD.S276314

45. Caillaud D, Chanez P, Escamilla R, et al. Asthma-COPD overlap syndrome (ACOS) vs 'pure' COPD: a distinct phenotype? Allergy. 2017;72(1):137-145. doi:10.1111/all.13004

46. Guerriero M, Caminati M, Viegi G, et al. Prevalence and features of asthma-chronic obstructive pulmonary disease overlap in Northern Italy general population. J Asthma. 2019;56(1):27-33. doi:10.1080/02770903.2018.1424190

47. Jo YS, Lee J, Yoon HI, et al. Different prevalence and clinical characteristics of asthma-chronic obstructive pulmonary disease overlap syndrome according to accepted criteria. Ann Allergy Asthma Immunol. 2017;118(6):696-703.e691. doi:10.1016/j. anai.2017.04.010

48. Bateman ED, Reddel HK, van Zyl-smit RN, et al. The asthma-COPD overlap syndrome: towards a revised taxonomy of chronic airways diseases? Lancet Respir Med. 2015;3 (9):719-728. doi:10.1016/S2213-2600(15)00254-4

49. Hansel NN, Paré PD, Rafaels N, et al. Genome-Wide Association Study Identification of Novel Loci Associated with Airway Responsiveness in Chronic Obstructive Pulmonary Disease. Am J Respir Cell Mol Biol. 2015;53(2):226-234. doi:10.1165/ rcmb.2014-01980C

50. Obeidat M, Faiz A, Li X, et al. The pharmacogenomics of inhaled corticosteroids and lung function decline in COPD. Eur Respir $J$. 2019;54(6):1900521. doi:10.1183/13993003.00521-2019

51. Tamada T, Sugiura H, Takahashi T, et al. Biomarker-based detection of asthma-COPD overlap syndrome in COPD populations. Int J Chron Obstruct Pulmon Dis. 2015;10:2169-2176. doi:10.2147/COPD.S88274

52. Izuhara K, Barnes PJ. Can we define asthma-COPD overlap (ACO) by biomarkers? J Allergy Clin Immunol Pract. 2019;7 (1):146-147. doi:10.1016/j.jaip.2018.07.002

53. Gava G, Núñez A, Esquinas C, et al. Analysis of blood biomarkers in patients with Chronic Obstructive Pulmonary Disease (COPD) and with Asthma-COPD Overlap (ACO). COPD. 2020;17(3):306-310. doi:10.1080/15412555.2020.1761314

54. de Llano LP, Cosío BG, Iglesias A, et al. Mixed Th2 and non-Th2 inflammatory pattern in the asthma-COPD overlap: a network approach. Int J Chron Obstruct Pulmon Dis. 2018;13:591-601. doi:10.2147/COPD.S153694

55. Hersh CP, Zacharia S, Prakash Arivu Chelvan R, et al.; COPDGene ${ }^{\circledR}$ Investigators. Immunoglobulin $\mathrm{E}$ as a biomarker for the overlap of atopic asthma and chronic obstructive pulmonary disease. Chronic Obstr Pulm Dis. 2020;7(1):1-12. doi:10.15326/jcopdf.7.1.2019.0138
56. Zeki AA, Schivo M, Chan A, et al. The asthma-COPD overlap syndrome: a common clinical problem in the elderly. J Allergy. 2011;2011:861926. doi:10.1155/2011/861926

57. Barnes PJ, Kharitonov SA. Exhaled nitric oxide: a new lung function test. Thorax. 1996;51(3):233-237. doi:10.1136/thx.51.3.233

58. Burrows B, Hasan FM, Barbee RA, et al. Epidemiologic observations on eosinophilia and its relation to respiratory disorders. $\mathrm{Am}$ Rev Respir Dis. 1980;122(5):709-719. doi:10.1164/ arrd.1980.122.5.709

59. Platts-Mills T. The role of immunoglobulin $\mathrm{E}$ in allergy and asthma. Am J Respir Crit Care Med. 2001;164(8 Pt 2):S1-S5. doi:10.1164/ajrccm.164.supplement_1.2103024

60. Kobayashi S, Hanagama M, Yamanda S, et al. Inflammatory biomarkers in asthma-COPD overlap syndrome. Int $J$ Chron Obstruct Pulmon Dis. 2016;11:2117-2123. doi:10.2147/COPD. S113647

61. Toledo-Pons N, van Boven JFM, Román-Rodríguez M, et al. ACO: time to move from the description of different phenotypes to the treatable traits. PLoS One. 2019;14(1):e0210915. doi:10.1371/journal.pone.0210915

62. Shirai T, Hirai K, Gon Y, et al. Combined assessment of serum periostin and YKL-40 may identify asthma-COPD overlap. J Allergy Clin Immunol Pract. 2019;7:134-145. doi:10.1016/j. jaip.2018.06.015

63. Ding Q, Sun S, Zhang Y, et al. Serum IL-8 and VEGFA are two promising diagnostic biomarkers of asthma-COPD overlap syndrome. Int J Chron Obstruct Pulmon Dis. 2020;15:357-365. doi:10.2147/COPD.S233461

64. Ghosh N, Choudhury P, Kaushik SR, et al. Metabolomic fingerprinting and systemic inflammatory profiling of asthma COPD overlap (ACO). Respir Res. 2020;21(1):126. doi:10.1186/s12931020-01390-4

65. Asensio VJ, Tomás A, Iglesias A, et al. Eosinophilic COPD Patients Display a Distinctive Serum miRNA Profile From Asthma and Non-eosinophilic COPD. Arch Bronconeumol. 2020;56(4):234-241. doi:10.1016/j.arbres.2019.09.020

66. Lacedonia D, Palladino GP, Foschino-Barbaro MP, et al. Expression profiling of miRNA-145 and miRNA-338 in serum and sputum of patients with COPD, asthma, and asthma-COPD overlap syndrome phenotype. Int J Chron Obstruct Pulmon Dis. 2017;12:1811-1817. doi:10.2147/COPD.S130616

67. Kumbhare S, Strange C. Mortality in asthma-chronic obstructive pulmonary disease overlap in the United States. South Med J. 2018;111(5):293-298. doi:10.14423/SMJ.0000000000000807

68. Baarnes CB, Andersen ZJ, Tjønneland A, et al. Incidence and long-term outcome of severe asthma-COPD overlap compared to asthma and COPD alone: a 35-year prospective study of 57,053 middle-aged adults. Int $J$ Chron Obstruct Pulmon Dis. 2017;12:571-579. doi:10.2147/COPD.S123167

69. van Boven JF, Román-Rodríguez $\mathrm{M}$, Palmer JF, et al. Comorbidome, pattern, and impact of asthma-COPD overlap syndrome in real life. Chest. 2016;149(4):1011-1020. doi:10.1016/j.chest.2015.12.002

70. Golpe R, Suárez-Valor M, Martín-Robles I, et al. Mortality in COPD patients according to clinical phenotypes. Int J Chron Obstruct Pulmon Dis. 2018;13:1433-1439. doi:10.2147/COPD. S159834

71. Peltola L, Pätsi H, Harju T. COPD Comorbidities Predict High Mortality - Asthma-COPD-Overlap Has Better Prognosis. COPD. 2020;17(4):366-372. doi:10.1080/15412555.2020.1783647

72. Sorino C, Pedone C, Scichilone N. Fifteen-year mortality of patients with asthma-COPD overlap syndrome. Eur J Intern Med. 2016;34:72-77. doi:10.1016/j.ejim.2016.06.020

73. Bai JW, Mao B, Yang WL, et al. Asthma-COPD overlap syndrome showed more exacerbations however lower mortality than COPD. QJM. 2017;110(7):431-436. doi:10.1093/qjmed/hcx005 
74. Suzuki M, Makita H, Konno S, et al. Asthma-like features and clinical course of chronic obstructive pulmonary disease. An Analysis from the Hokkaido COPD Cohort Study. Am J Respir Crit Care Med. 2016;194(11):1358-1365. doi:10.1164/ recm.201602-0353OC

75. Maselli DJ, Hanania NA. Management of asthma COPD overlap. Ann Allergy Asthma Immunol. 2019;123(4):335-344. doi:10.1016/j.anai.2019.07.021

76. Pauwels RA, Pedersen S, Busse WW, et al. Early intervention with budesonide in mild persistent asthma: a randomised, double-blind trial. Lancet. 2003;361(9363):1071-1076. doi:10.1016/S0140-6736(03)12891-7

77. Busse WW, Pedersen S, Pauwels RA, et al. The inhaled steroid treatment as regular therapy in early asthma (START) study 5-year follow-up: effectiveness of early intervention with budesonide in mild persistent asthma. J Allergy Clin Immunol. 2008;121(5):1167-1174. doi:10.1016/j.jaci.2008.02.029

78. Castle W, Fuller R, Hall J, et al. Serevent nationwide surveillance study: comparison of salmeterol with salbutamol in asthmatic patients who require regular bronchodilator treatment. $B M J$. 1993;306(6884):1034-1037. doi:10.1136/bmj.306.6884.1034

79. Nelson HS, Weiss ST, Bleecker ER, et al. The Salmeterol Multicenter Asthma Research Trial: a comparison of usual pharmacotherapy for asthma or usual pharmacotherapy plus salmeterol. Chest. 2006;129(1):15-26. doi:10.1378/ chest.129.1.15

80. Maselli DJ, Hardin M, Christenson SA, et al. Clinical approach to the therapy of asthma-COPD overlap. Chest. 2019;155 (1):168-177. doi:10.1016/j.chest.2018.07.028

81. Amegadzie JE, Gorgui J, Acheampong L, et al. Comparative safety and effectiveness of inhaled bronchodilators and corticosteroids for treating asthma-COPD overlap: a systematic review and meta-analysis. $J$ Asthma. 2019:1-16.

82. Stolz D, Hirsch HH, Schilter D, et al. Intensified therapy with inhaled corticosteroids and long-acting $\beta 2$-agonists at the onset of upper respiratory tract infection to prevent chronic obstructive pulmonary disease exacerbations. A Multicenter, Randomized, Double-Blind, Placebo-controlled Trial. Am J Respir Crit Care Med. 2018;197(9):1136-1146. doi:10.1164/rccm.201709-1807OC

83. Welte T, Miravitlles M, Hernandez P, et al. Efficacy and tolerability of budesonide/formoterol added to tiotropium in patients with chronic obstructive pulmonary disease. Am J Respir Crit Care Med. 2009;180(8):741-750. doi:10.1164/rccm.2009040492OC

84. Jung KS, Park HY, Park SY, et al. Comparison of tiotropium plus fluticasone propionate/salmeterol with tiotropium in COPD: a randomized controlled study. Respir Med. 2012;106 (3):382-389. doi:10.1016/j.rmed.2011.09.004

85. Lipson DA, Barnacle H, Birk R, et al. FULFIL Trial: once-daily triple therapy for patients with chronic obstructive pulmonary disease. Am J Respir Crit Care Med. 2017;196(4):438-446. doi:10.1164/rccm.201703-0449OC

86. Rabe KF, Martinez FJ, Ferguson GT, et al. Triple inhaled therapy at two glucocorticoid doses in moderate-to-very-severe COPD. N Engl J Med. 2020;383(1):35-48. doi:10.1056/NEJMoa1916046

87. Kew KM, Dahri K. Long-acting muscarinic antagonists (LAMA) added to combination long-acting beta2-agonists and inhaled corticosteroids (LABA/ICS) versus LABA/ICS for adults with asthma. Cochrane Database Syst Rev. 2016;1:CD011721. doi:10.1002/14651858.CD009704.pub2

88. Lee LA, Bailes Z, Barnes N, et al. Efficacy and safety of once-daily single-inhaler triple therapy (FF/UMEC/VI) versus $\mathrm{FF} / \mathrm{VI}$ in patients with inadequately controlled asthma (CAPTAIN): a double-blind, randomised, Phase 3A trial. Lancet Respir Med. 2021;9(1):69-84. doi:10.1016/S2213-2600(20) 30389-1
89. Gessner C, Kornmann O, Maspero J, et al. Fixed-dose combination of indacaterol/glycopyrronium/mometasone furoate once-daily versus salmeterol/fluticasone twice-daily plus tiotropium once-daily in patients with uncontrolled asthma: a randomised, Phase IIIb, non-inferiority study (ARGON). Respir Med. 2020;170:106021. doi:10.1016/j.rmed.2020.106021

90. Ishiura Y, Fujimura M, Ohkura N, et al. Effect of triple therapy in patients with asthma-COPD overlap. Int J Clin Pharmacol Ther. 2019;57(8):384-392. doi:10.5414/CP203382

91. Martinez FJ, Rabe KF, Calverley PMA, et al. Determinants of response to roflumilast in severe chronic obstructive pulmonary disease. Pooled Analysis of Two Randomized Trials. Am J Respir Crit Care Med. 2018;198(10):1268-1278. doi:10.1164/ rccm.201712-2493OC

92. Bateman ED, Goehring UM, Richard F, Watz H. Roflumilast combined with montelukast versus montelukast alone as add-on treatment in patients with moderate-to-severe asthma. $J$ Allergy Clin Immunol. 2016;138(1):142-149. doi:10.1016/j.jaci.2015.11.035

93. Kim SW, Kim JH, Park CK, et al. Effect of roflumilast on airway remodelling in a murine model of chronic asthma. Clin Exp Allergy. 2016;46(5):754-763. doi:10.1111/cea.12670

94. Price D, Popov TA, Bjermer L, et al. Effect of montelukast for treatment of asthma in cigarette smokers. J Allergy Clin Immunol. 2013;131(3):763-771. doi:10.1016/j.jaci.2012.12.673

95. Normansell R, Walker S, Milan SJ, et al. Omalizumab for asthma in adults and children. Cochrane Database Syst Rev. 2014;1: CD003559.

96. Ortega HG, Liu MC, Pavord ID, et al. Mepolizumab treatment in patients with severe eosinophilic asthma. $N$ Engl J Med. 2014;371 (13):1198-1207. doi:10.1056/NEJMoa1403290

97. Castro M, Zangrilli J, Wechsler ME, et al. Reslizumab for inadequately controlled asthma with elevated blood eosinophil counts: results from two multicentre, parallel, double-blind, randomised, placebo-controlled, phase 3 trials. Lancet Respir Med. 2015;3 (5):355-366. doi:10.1016/S2213-2600(15)00042-9

98. FitzGerald JM, Bleecker ER, Nair P, et al. Benralizumab, an antiinterleukin-5 receptor $\alpha$ monoclonal antibody, as add-on treatment for patients with severe, uncontrolled, eosinophilic asthma (CALIMA): a randomised, double-blind, placebo-controlled phase 3 trial. Lancet. 2016;388(10056):2128-2141. doi:10.1016/ S0140-6736(16)31322-8

99. Castro M, Corren J, Pavord ID, et al. Dupilumab efficacy and safety in moderate-to-severe uncontrolled asthma. $N$ Engl J Med. 2018;378(26):2486-2496. doi:10.1056/NEJMoa1804092

100. Maltby S, Gibson PG, Powell H, et al. Omalizumab treatment response in a population with severe allergic asthma and overlapping COPD. Chest. 2017;151(1):78-89. doi:10.1016/j. chest.2016.09.035

101. Hanania NA, Chipps BE, Griffin NM, et al. Omalizumab effectiveness in asthma-COPD overlap: post hoc analysis of PROSPERO. J Allergy Clin Immunol. 2019;143(4):1629-1633. e2. doi:10.1016/j.jaci.2018.11.032

102. Pavord ID, Chanez P, Criner GJ, et al. Mepolizumab for eosinophilic chronic obstructive pulmonary disease. $N$ Engl $J$ Med. 2017;377(17):1613-1629. doi:10.1056/NEJMoa1708208

103. Criner GJ, Celli BR, Brightling CE, et al. Benralizumab for the prevention of COPD exacerbations. $N$ Engl J Med. 2019;381 (11):1023-1034. doi:10.1056/NEJMoa1905248

104. Criner GJ, Celli BR, Singh D, et al. Predicting response to benralizumab in chronic obstructive pulmonary disease: analyses of GALATHEA and TERRANOVA studies. Lancet Respir Med. 2020;8(2):158-170. doi:10.1016/S2213-2600(19)30338-8

105. Krishnan JK, Voelker H, Connett JE, et al. Effect of daily azithromycin therapy and adherence on readmission risk in COPD. Eur Respir J. 2019;53(3):1801377. doi:10.1183/13993003.013772018 
106. Uzun S, Djamin RS, Kluytmans JA, et al. Azithromycin maintenance treatment in patients with frequent exacerbations of chronic obstructive pulmonary disease (COLUMBUS): a randomised, double-blind, placebo-controlled trial. Lancet Respir Med. 2014;2(5):361-368. doi:10.1016/S2213-2600(14) 70019-0

107. Albert RK, Connett J, Bailey WC, et al. Azithromycin for prevention of exacerbations of COPD. $N$ Engl J Med. 2011;365 (8):689-698. doi:10.1056/NEJMoa1104623

108. Gibson PG, Yang IA, Upham JW, et al. Effect of azithromycin on asthma exacerbations and quality of life in adults with persistent uncontrolled asthma (AMAZES): a randomised, double-blind, placebo-controlled trial. Lancet. 2017;390(10095):659-668. doi:10.1016/S0140-6736(17)31281-3

109. Nagai A. [Guidelines for the diagnosis and management of chronic obstructive pulmonary disease: 3rd edition]. Nihon Rinsho. 2011;69(10):1729-1734. Japanese.

110. Miravitlles M, Soler-Cataluña JJ, Calle M, et al. Spanish COPD guidelines (GesEPOC). Pharmacological treatment of stable COPD. Arch Bronconeumol. 2012;48:247-257. doi:10.1016/j. arbres.2012.04.001

111. Soler-Cataluña JJ, Cosío B, Izquierdo JL, et al. Consensus document on the overlap phenotype COPD-asthma in COPD. Arch Bronconeumol. 2012;48:331-337. doi:10.1016/j.arbres.2011.12.009

112. Koblizek V, Chlumsky J, Zindr V, et al. Chronic Obstructive Pulmonary Disease: official diagnosis and treatment guidelines Biomed of the Czech Pneumological and Phthisiological society: a novel phenotypic approach to COPD with patient oriented care. Pap Med Fac Univ Palacky Olomouc Czech Repub. 2013;157:189-201. doi:10.5507/bp.2013.039

113. Kankaanranta H, Harju T, Kilpeläinen M, et al. Diagnosis and pharmacotherapy of stable chronic obstructive pulmonary disease: the Finish guidelines. Basic Clin Pharmacol Toxicol. 2015;116:291-307. doi:10.1111/bcpt.12366

114. Mahboud BH, Vats MG, Al Zaabi A, et al. Joint Statement for the diagnosis, management, and prevention of chronic obstructive pulmonary disease for Gulf Cooperation Council countries and Middle East-North Africa region, 2017. Int J Chron Obstruct Pulmon Dis. 2017;12:2869-2890. doi:10.2147/COPD.S136245

115. Plaza V, Alvarez F, Calle M, et al. Consensus on the asthma-COPD overlap syndrome (ACOS) between the Spanish COPD guidelines (GesEPOC) and the Spanish guidelines on the management of asthma (GEMA). Arch Bronconeumol. 2017;53:443-449. doi:10.1016/j.arbres.2017.04.002
116. Miravitlles M. Diagnosis of asthma-COPD overlap: the five commandments. Eur Respir J. 2017;49:1700506. doi:10.1183/ 13993003.00506-2017

117. Araújo D, Padrão E, Morais-Almeida M, et al. Asthma-chronic obstructive pulmonary disease overlap syndrome - Literature review and contributions towards a Portuguese consensus. Rev Port Pneumol. 2017;23(2):90-99. doi:10.1016/j.rppnen.2016.11.005

118. Global initiative for asthma (GINA) 2020 report. Available from: https://ginasthma.org/wp-content/uploads/2020/06/GINA-2020report 20_06_04-1-wms.pdf. Accessed March 23, 2021.

119. Bourbeau J, Bhutani M, Hernandez P, et al. Canadian Thoracic Society Clinical Practice Guideline on pharmacotherapy in patients with COPD - 2019 update of evidence. Can J Respir Crit Care Sleep Med. 2019;3(4):210-232. doi:10.1080/ 24745332.2019.1668652

120. Miravitlles M, Calle M, Molina J, et al. Update of the Spanish guideline for COPD (GesEPOC) 2021: pharmacological treatment of stable COPD. Arch Bronconeumol. 2021:S03002896(21)00103-4. doi:10.1016/j.arbres.2021.03.005

121. Montes de Oca M, López Varela MV, Acuña A, et al. Incorporating new evidence on inhaled medications in COPD. The Latin American Chest Association (ALAT) 2019. Arch Bronconeumol. 2020;56 (2):106-113. doi:10.1016/j.arbres.2019.09.023

122. Chalmers JD, Laska IF, Franssen FME, et al. Withdrawal of inhaled corticosteroids in chronic obstructive pulmonary disease: a European Respiratory Society Guideline. Eur Respir J. 2020;35:2000351. doi:10.1183/13993003.00351-2020

123. Miravitlles M. Asthma-COPD overlap (ACO) PRO-CON debate. ACO: call me by my name. COPD. 2020;17(5):471-473. doi:10.1080/15412555.2020.1817883

124. Papi A. Asthma COPD overlap PRO-CON debate. ACO: the Mistaken Term. COPD. 2020;17(5):474-476. doi:10.1080/ 15412555.2020.1817882

125. Marsh SE, Travers J, Weatherall M, et al. Proportional classifications of COPD phenotypes. Thorax. 2008;63(9):761-767. doi:10.1136/thx.2007.089193

126. Morgan BW, Grigsby MR, Siddharthan T, et al. Epidemiology and risk factors of asthma-chronic obstructive pulmonary disease overlap in low- and middle-income countries. J Allergy Clin Immunol. 2019;143 (4):1598-1606. doi:10.1016/j.jaci.2018.06.052

\section{Publish your work in this journal}

The International Journal of COPD is an international, peer-reviewed journal of therapeutics and pharmacology focusing on concise rapid reporting of clinical studies and reviews in COPD. Special focus is given to the pathophysiological processes underlying the disease, intervention programs, patient focused education, and self management protocols. This journal is indexed on PubMed Central, MedLine and CAS. The manuscript management system is completely online and includes a very quick and fair peer-review system, which is all easy to use. Visit http://www.dovepress.com/testimonials.php to read real quotes from published authors. 